\title{
Past and future mass balance of 'Ka Roimata o Hine Hukatere' Franz Josef Glacier, New Zealand
}

\author{
Brian ANDERSON, ${ }^{*}$ Wendy LAWSON, Ian OWENS, Becky GOODSELL \\ Department of Geography, University of Canterbury, Private Bag 4800, Christchurch, New Zealand \\ E-mail: brian.anderson@vuw.ac.nz
}

\begin{abstract}
Despite their relatively small total ice volume, mid-latitude valley glaciers are expected to make a significant contribution to global sea-level rise over the next century due to the sensitivity of their mass-balance systems to small changes in climate. Here we use a degree-day model to reconstruct the past century of mass-balance variation at 'Ka Roimata o Hine Hukatere' Franz Josef Glacier, New Zealand, and to predict how mass balance may change over the next century. Analysis of the relationship between temperature, precipitation and mass balance indicates that temperature is a stronger control than precipitation on the mass balance of Franz Josef Glacier. The glacier's mass balance, relative to its 1986 geometry, has decreased at a mean annual rate of $0.02 \mathrm{~m} \mathrm{a}^{-1}$ w.e. between 1894 and 2005. We compare this reduction to observations of terminus advance and retreat, of which Franz Josef Glacier has the best record in the Southern Hemisphere. For the years 2000-05 the relative mass balance ranged from -0.75 to $+1.50 \mathrm{~m} \mathrm{a}^{-1}$ w.e., with $2000 / 01$ the only year showing a negative mass balance. In a regionally downscaled Intergovernmental Panel on Climate Change mean warming scenario, the annual relative mass balance will continue to decrease at $0.02 \mathrm{ma}^{-1}$ w.e. through the next century.
\end{abstract}

\section{INTRODUCTION}

\subsection{Rationale}

Understanding how the mass balance of small glaciers responds to climate change is important for the interpretation of global climate change, and for understanding its impacts. Of the $0.20-0.86 \mathrm{~m}$ sea-level change that the Intergovernmental Panel on Climate Change (IPCC) predicts will occur by 2100 , it is estimated that $0.05-0.11 \mathrm{~m}$ will occur as a result of the melting of small glaciers (Houghton and others, 2001). Many interpretations of past environmental change in mid-latitudes, and of the links between Southern and Northern Hemisphere climate, are based on observations of glacier terminus position (Grove, 1988; Denton and Hendy, 1994; Lowell and others, 1995). Understanding these terminus position records in terms of climate requires knowledge of the link between climate and terminus behaviour. In this paper, we investigate the nature of the climate-mass-balance relationship for 'Ka Roimata o Hine Hukatere' Franz Josef Glacier, a mid-latitude glacier in the Southern Hemisphere.

\subsection{Franz Josef Glacier and previous work}

Franz Josef Glacier is a temperate maritime glacier, located on the western side of the Southern Alps of New Zealand (Fig. 1). It has the longest and most detailed record of terminus position in the Southern Hemisphere (Grove, 1988), and a wide range of research has been conducted there, including analyses of past mass-balance change (Woo and Fitzharris, 1992; Ruddell, 1995), sensitivity to climate change (Oerlemans, 1997) and projections of future change (Oerlemans and others, 1998). These latter studies have largely been based on mass-balance modelling using regional climate data, and have used terminus position

*Present address: Antarctic Research Centre, Victoria University of Wellington, PO Box 600, Wellington, New Zealand. rather than systematic mass-balance measurements to validate and/or tune the models. As a result, they produce vastly different estimates of annual accumulation and ablation from long-term mean annual temperature and precipitation values (Table 1).

In terms of understanding past mass balance, Woo and Fitzharris (1992) succeeded in producing an historic massbalance simulation and linking it to the pattern of terminus retreat and advance since 1910. However, in order to achieve this match, they had to tune their model in such a way that they considered their estimated net balances were unrealistically positive, given the general retreat of the glacier over the period. Ruddell (1995) tuned his model using terminus ablation rates: to enable a realistic match of his model results with known terminus position he had to assume annual ablation rates at the terminus of $40 \mathrm{ma}^{-1}$ w.e., which is nearly four times as large as the maximum measured annual ablation rate of any glacier reported to the World Glacier Monitoring Service, $11 \mathrm{~m} \mathrm{a}^{-1}$ w.e., (Haeberli and others, 2001) and twice that which will be reported in this study.

\subsection{Aims and approach}

The aim of this paper is to (1) develop a robust model of the mass-balance-climate system of Franz Josef Glacier based on direct measurements of mass balance and glacier climate, and (2) to use this measurement-calibrated model to examine past changes in mass balance and to predict future mass balance. This study concentrates on the behaviour of Franz Josef Glacier in the 20th and 21st centuries. A degree-day approach is used for modelling. The parameters of the model are calculated using measurements from a 3 year programme monitoring glacier climate and mass balance. The model is evaluated against a further 2 years of mass-balance measurements. Interpretation of past changes in mass balance is based on climate data recorded since 1894 at Hokitika, approximately $100 \mathrm{~km}$ to the northeast of Franz Josef Glacier, 


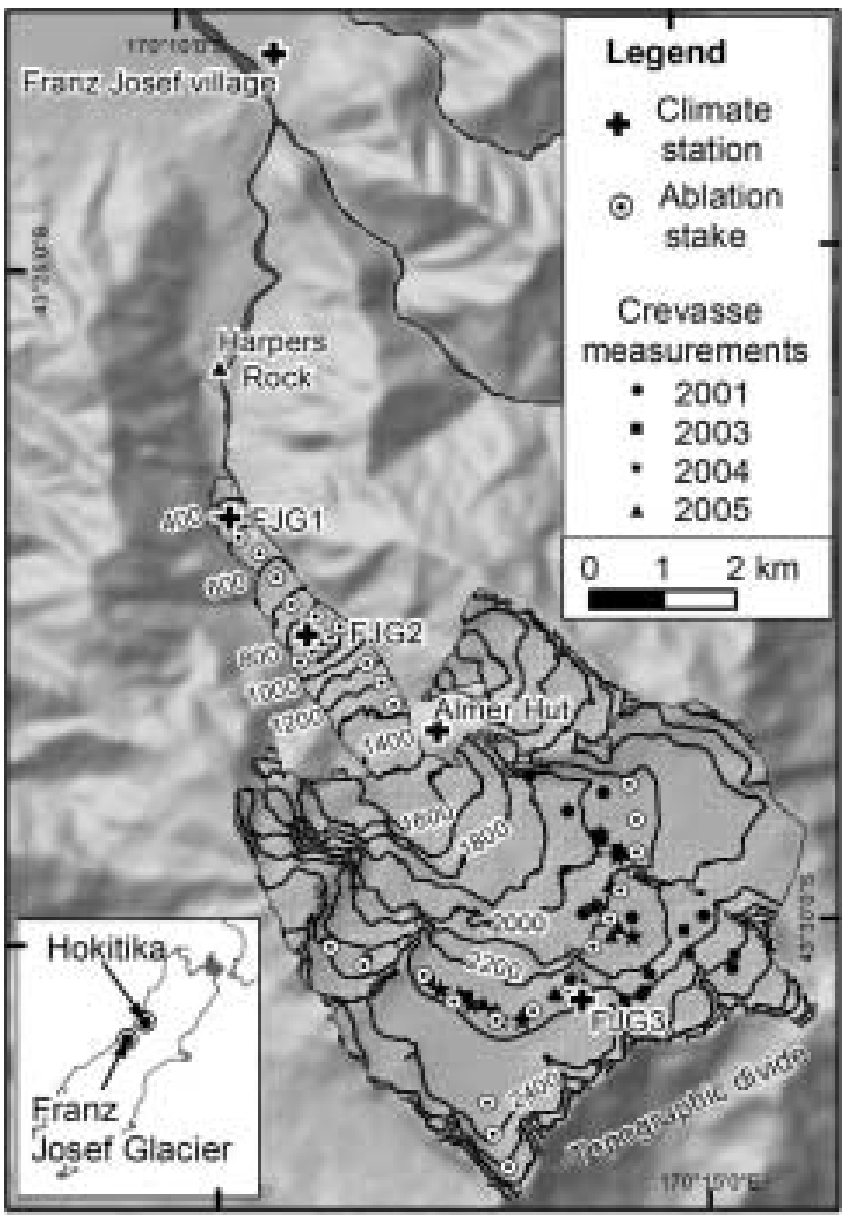

Fig. 1. Location map for Franz Josef Glacier, on the west coast of the South Island of New Zealand. Long-term climate stations are at Franz Josef village and Hokitika. A short-term climate station was run at Almer Hut by the National Institute of Water and Atmospheric Research, New Zealand, from 1991 to 1995, and the stations FJG1-FJG3 were installed from 2000 to 2003 as part of this study. Contour heights are in ma.s.l., and glacier length is measured relative to Harpers Rock. Mass balance was measured using stakes year-round below $1400 \mathrm{~m}$, and in summer only on the upper glacier. Crevasse stratigraphy measurement locations are limited to accessible areas with large crevasses.

calibrated against a local record, at Franz Josef village (Fig. 1). Future mass balance is predicted in the context of regionally adjusted IPCC scenarios.

\section{DEGREE-DAY MODELLING}

Degree-day glacier mass-balance models allow the calculation of accumulation, ablation and net mass balance from simple climate variables. Ablation is calculated from air temperature, and accumulation is calculated from precipitation using a temperature threshold to discriminate rain from snow. The model used here is similar to those of Jóhannesson and others (1995) and Braithwaite and Zhang (2000). Temperature and precipitation are the only climate input data required.

The degree-day model calculates daily mass balance from daily climate data, with the inclusion of empirical constants based on detailed climate data to incorporate the effects of sub-daily variation. The model assumes that elevation is the only controlling spatial variable.
Table 1. Comparison of model output for previous mass-balance models at Franz Josef Glacier

\begin{tabular}{|c|c|c|}
\hline Study & $\begin{array}{l}\text { Net annual ablation } \\
\text { at } 300 \text { ma.s.l. }\end{array}$ & $\begin{array}{c}\text { Net annual } \\
\text { accumulation } \\
\text { at } 2500 \text { ma.s.l. }{ }^{\dagger}\end{array}$ \\
\hline
\end{tabular}

m w.e.

mw.e.

$\begin{array}{lll}\text { Woo and Fitzharris (1992) } & 22 & 9.9 \\ \text { Ruddell (1995) } & 40 & 8.5 \\ \text { Oerlemans (1997) } & 22 & 5.0\end{array}$

*Ruddell (1995) and Oerlemans (1997) calculate net annual ablation from long-term mean annual temperature. For Woo and Fitzharris (1992) it is calculated using their degree-day factors and lapse rates.

${ }^{\dagger}$ Estimated from the mean annual precipitation value used at $2500 \mathrm{~m}$ a.s.l. in each study.

In the model, accumulation (snowfall) occurs on days when precipitation, $p$, is greater than zero and the temperature, $T$, is lower than a threshold temperature, $T_{\text {crit. }}$. A value of $T_{\text {crit }}=1{ }^{\circ} \mathrm{C}$ has been determined from best-fit modelling in accumulation models for New Zealand (Moore and Owens, 1984; Barringer, 1989), and that value is used here. Accumulation, $c$, at elevation $z$ is given in terms of the mean daily temperature, $T_{\text {mean, }}$ and total daily precipitation, $p_{\text {total }}$, by:

$$
c(z)=f_{C}\left(T_{\text {mean }}\right) p_{\text {total }}(z),
$$

where $f_{c}$ is the accumulation function, an empirical function representing the proportion of the day that $T<T_{\text {crit. }}$. The form of $f_{c}$ is derived from analysis of hourly temperature data. Precipitation, $p_{\text {total, }}$ is assumed to fall uniformly throughout the day.

Ablation, $a$, at elevation $z$ is assumed to be proportional to the daily average of hourly positive temperatures, $T_{\text {pos, }}$ where:

$$
T_{\text {pos }}(z)=\frac{1}{24} \sum_{\text {hour }=1}^{24} T_{\text {hour }}(z), \quad T_{\text {hour }}(z)>0 .
$$

Ablation may then be calculated at elevation $z$ as follows:

$$
a(z)=k T_{\text {pos }}(z),
$$

where $k$ is the degree-day factor, derived here empirically from measurements of temperature and ablation. $T_{\text {pos }}$ is obtained from $T_{\text {mean }}$ as follows:

$$
T_{\text {pos }}(z)=f_{\mathrm{a}}\left(T_{\text {mean }}\right)
$$

in which the ablation function $f_{\mathrm{a}}$ is derived from analysis of hourly temperature data.

To calculate mass balance, $B$, over the entire glacier for the balance year, the glacier is split into $n$ elevation bands, and the daily totals of accumulation and ablation for each elevation band are summed:

$$
B=\sum_{t=1 \text { April }}^{31} \sum_{i=1}^{n} A\left(z_{i}\right)\left[c\left(t, z_{i}\right)+a\left(t, z_{i}\right)\right]
$$

where $z_{i}$ is the mid-elevation of elevation band $i$ and $A\left(z_{i}\right)$ is the area of the glacier in elevation band $i$.

In order to implement the degree-day model as formulated above, the required input data are:

The hypsometry of the glacier, $A(z)$;

The variation of precipitation and temperature with elevation, $T(z)$ and $p(z)$; 
Measurements of daily temperature, $T_{\text {mean, }}$ and precipitation, $p_{\text {total, }}$ for the period of interest.

The following model parameters are required:

Accumulation function, $f_{c}$;

Ablation function, $f_{\mathrm{a}}$;

Degree-day factor $k$.

These required input data and model parameters are discussed in the rest of this section.

\subsection{Meteorological input data}

The meteorological input data for the model come from a number of records. The longest record is of temperature and precipitation at Hokitika, $100 \mathrm{~km}$ to the northeast of the glacier (Fig. 1). This record is essentially complete since 1894, coinciding with the first survey of the glacier (Harper, 1894). Site changes at this station have been analyzed and corrections calculated (Salinger, 1981; Gellatly and Norton, 1984). In comparison, the record at Franz Josef village, $7 \mathrm{~km}$ to the north of the glacier, is complete only from 1956, the station has had a number of site changes and the site notes indicate that it has often been in poor condition (Salinger, 1981). The record is used from 1982 to define the relationship between Hokitika temperature and precipitation and Franz Josef village temperature and precipitation.

There have been a number of sites within the glacier valley where precipitation has previously been measured for a few months to a few years. These records are described by Griffiths and McSaveney (1983) and have generally used storage rain gauges. These short-term data have been normalized to the longer-term Franz Josef village data (1941-70) to obtain long-term annual precipitation estimates from these sites (Griffiths and McSaveney, 1983). Data from an additional site at 1700 ma.s.l. (Almer Hut; see Fig. 1) have been used in this study to define the precipitation at higher elevations, and the same normalization procedure has been used to obtain a long-term annual precipitation estimate. These data are used to define the variation of precipitation with elevation used in the model.

For this study, temperature was measured at three sites on the glacier at 400, 800 and 2300 ma.s.l. (Fig. 1), between 2000 and 2003. Sensors were Hobo and Campbell Scientific temperature probes mounted $2 \mathrm{~m}$ above the glacier surface. These data are used to define the variation of temperature with elevation used in the model, by reference to each other and the data collected at Franz Josef village for overlapping time periods.

\subsection{Glacier hypsometry}

The surface elevation of Franz Josef Glacier ranges from $\sim 300$ to $\sim 3000 \mathrm{~m}$ (Fig. 1). For the purposes of our model, this range is discretized into $136 \times 20 \mathrm{~m}$ wide elevation bands based on a digital elevation model (DEM) from the most recent contour map (NZMS 260: H35, I35). This map is based on 1986 aerial photography, and has an estimated uncertainty in elevation of $\pm 10 \mathrm{~m}$. While the glacier has changed significantly near the terminus since 1986, this DEM remains the only complete topographic dataset of the glacier. A fixed glacier geometry is used for the massbalance modelling. We refer to mass balance calculated on this fixed geometry as the 'relative mass balance'.

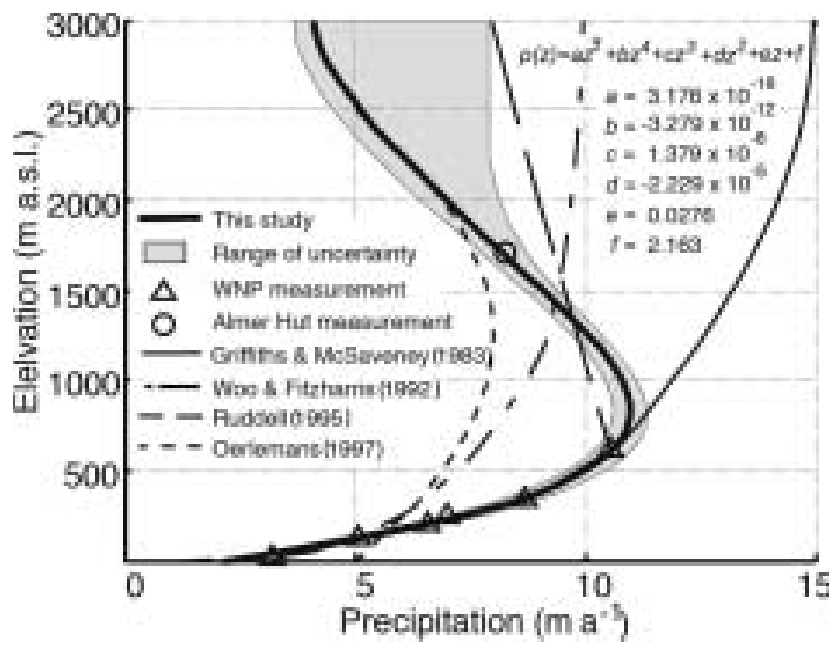

Fig. 2. The polynomial relationship between annual precipitation totals and elevation, $p(z)$, for Franz Josef Glacier used as input to the degree-day mass-balance model (thick line). Curves used by previous studies are also shown. The Westland National Park (WNP) measurements were reported by Griffiths and McSaveney (1983); these and the Almer Hut data are normalized to the long-term mean annual rainfall as explained in the text. Uncertainty in the distribution is denoted by the shaded area, as explained in the text.

This approach does not include the dynamic response of the glacier, which moves the glacier towards a zero massbalance state. Consequently, model output in this study is a direct reflection of climate variation and its influence on mass-balance variation, rather than absolute mass balance. Previous reconstructions of the mass balance of Franz Josef Glacier (Woo and Fitzharris, 1992; Ruddell, 1995) have adjusted the glacier geometry through the period of calculation.

\subsection{Precipitation distribution}

The distribution of precipitation with elevation, $p(z)$, at Franz Josef Glacier is critical to the calculation of mass balance (Oerlemans, 1997), but difficult to derive empirically because of the well-known difficulties of measuring precipitation at high elevations in mountainous terrain. The curve for the distribution used here (Fig. 2, heavy line) is well constrained at low elevations $(<600 \mathrm{~m}$ a.s.l.) by data reported by Griffiths and McSaveney (1983) and at a higher elevation by the data from Almer Hut. These data are combined with the finding that the regional precipitation maximum for the Southern Alps lies to the northwest of the main topographic divide (Fig. 1; Griffiths and McSaveney, 1983; Henderson and Thompson, 1999), which confirms the measured reduction in precipitation towards the head of the glacier.

A precipitation maximum of approximately $11 \mathrm{ma}^{-1}$ is found near $1200 \mathrm{ma.s.l.}$ reducing to $8.2 \mathrm{~m} \mathrm{a}^{-1}$ at $1700 \mathrm{~m}$ a.s.l. Above this elevation, precipitation reduces to $5.1 \mathrm{~m} \mathrm{a}^{-1}$ at $2500 \mathrm{~m}$ a.s.I. Precipitation above $1700 \mathrm{~m}$ a.s.l. is established from comparison with net accumulation measurements (see section 3) and includes effects such as the reduction in accumulation resulting from wind redistribution of snow.

An estimate of the uncertainty in this curve is provided from the maximum standard error of estimate provided by Griffiths and McSaveney (1983) and is applied up to $1700 \mathrm{~m}$ a.s.I. Beyond this elevation the minimum precipitation is constrained by net accumulation measurements 


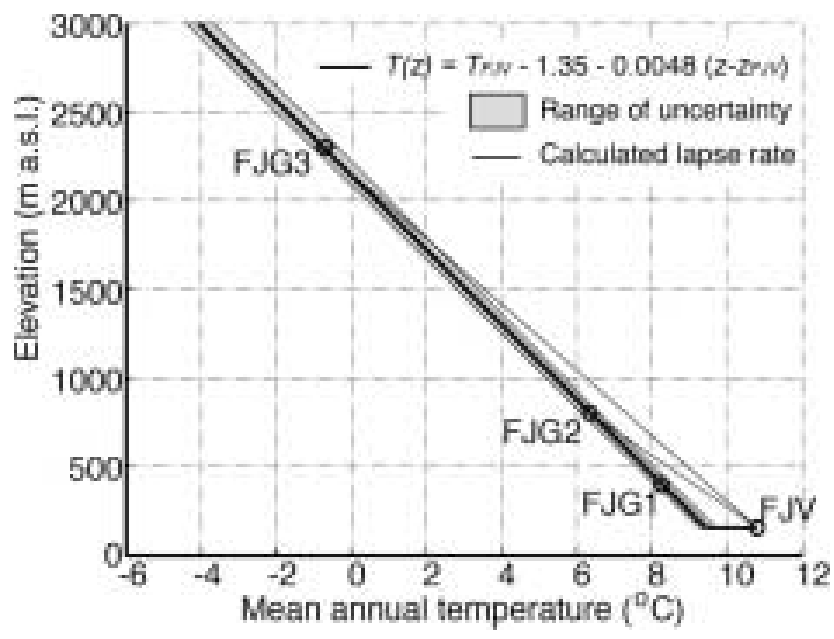

Fig. 3. The relationship between temperature and elevation for Franz Josef Glacier used in this study. A temperature step of $1.35^{\circ} \mathrm{C}$ at the elevation of the Franz Josef village climate station, and a lapse rate of $0.0048^{\circ} \mathrm{Cm}^{-1}$ are used. $T_{\mathrm{FJV}}$ denotes temperature measured at Franz Josef village, and $z_{\mathrm{FJV}}$ is the elevation of Franz Josef village (155 ma.s.l.). The mean annual temperatures at FJG1FJG3 have been calculated from long-term mean annual temperature at Franz Josef Glacier, as explained in the text.

(see section 3), and the maximum by the measurement at $1700 \mathrm{~m}$ a.s.l., as there is no indication of a second peak in precipitation west of the divide in other transects across the Southern Alps (Griffiths and McSaveney, 1983; Henderson and Thompson, 1999). The value of precipitation within this range (Fig. 2, thick line) has been chosen by further testing of the mass-balance model described here, with a simple flowline model and the present-day length of the glacier (Anderson, 2004).

Previous mass-balance models at Franz Josef Glacier have characterized the distribution of precipitation with elevation in various ways (Fig. 2). The estimates of Griffiths and McSaveney (1983) and Woo and Fitzharris (1992) do not have a peak in precipitation, but suggest that the precipitation increases monotonically with elevation. Ruddell (1995) and Oerlemans (1997) do indicate a lowering of precipitation towards the head of the glacier, but the location of the peak, and the value at the head of the glacier are quite different. In contrast, we have defined the location of the peak, although the precipitation at the head of the glacier is still poorly constrained.

\subsection{Temperature distribution}

The distribution of temperature with elevation, $T(z)$, that we use (Fig. 3) is determined from a combination of measurements from the three temporary glacier climate stations and long-term data from the permanent Franz Josef village station. Lapse rates have been calculated between Franz Josef village and the stations FJG2 and FJG3 (Fig. 1), and used to calculate mean annual temperatures at these stations (Fig. 3). The lapse rate between the mean annual temperatures at FJG2 and FJG3 is $0.0048^{\circ} \mathrm{Cm}^{-1}$, compatible with that calculated directly between the stations FJG1FJG2 and FJG2-FJG3. This lapse rate implies an abrupt change in temperature of $T_{\mathrm{s}}=1.35^{\circ} \mathrm{C}$ at $155 \mathrm{~m}$ a.s.l., between Franz Josef village on the coastal plain and the first glacier climate station. This is a 'glacier cooling effect', where temperatures at a glacier climate station are lower than temperatures at an ice-free climate station at the same elevation (Braithwaite and others, 2002).

The uncertainty in this temperature distribution has been estimated from the range of mean annual temperatures at FJG2 and FJG3 calculated from the 95\% confidence intervals of the lapse rates from Franz Josef village, resulting in a range in the temperature step, $T_{\mathrm{s}}$, of $1.09-1.54^{\circ} \mathrm{C}$.

\subsection{Accumulation function}

As indicated earlier (Equation (1)), the accumulation function, $f_{C}$, represents the proportion of precipitation that falls while the temperature is lower than the critical temperature $T_{\text {crit }}=1{ }^{\circ} \mathrm{C}$. The form of this function is derived from hourly measurements of temperature at the three glacier climate stations (FJG1-FJG3; Fig. 1), and a piecewise linear function is fitted to the relationship between measured mean daily temperature, $T_{\text {mean, }}$ and the proportion of the day that $T<T_{\text {crit: }}$ :

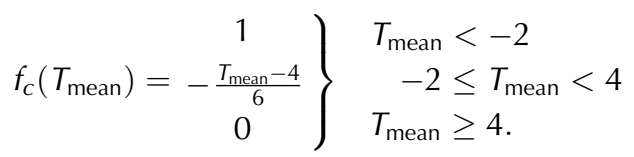

Thus, when the mean daily temperature, $T_{\text {mean, }}$ is less than $-2{ }^{\circ} \mathrm{C}$ all precipitation falls as snow, and when $T_{\text {mean }}$ is greater than $4^{\circ} \mathrm{C}$ all precipitation falls as rain. In between, the proportion varies between these extremes. This accumulation function, $f_{c}$, in combination with $p(z)$ (Fig. 2) and $T(z)$ (Fig. 3), allows the calculation of accumulation at any elevation on the glacier.

\subsection{Ablation function}

To calculate ablation using the degree-day method, the daily temperature needs to be related to the daily positive temperature sum, $T_{\text {pos, }}$ as indicated in Equation (4). The mean of the daily minimum and maximum temperatures is chosen as the input to the degree-day model because of the strong correlation between this quantity and mean daily temperature at each of the three glacier climate stations ( $r=0.98$ for the period 2000-03).

In order to calculate the relationship between the daily mean temperature, $T_{\text {mean, }}$ and the daily positive temperature sum, $T_{\text {pos, }}$ the mean of minimum and maximum daily temperatures measured at each of the three glacier climate stations is compared with the daily positive temperature sum (see Equation (2)), measured hourly, at the same station. A strong piecewise linear relationship $(r=0.98)$ is found of the form:

$$
\left.T_{\text {pos }}=f_{\mathrm{a}}\left(T_{\text {mean }}\right)=\begin{array}{c}
0 \\
T_{\text {mean }}-0.4
\end{array}\right\} \begin{gathered}
T_{\text {mean }}<0.4 \\
T_{\text {mean }} \geq 0.4
\end{gathered}
$$

Combined with the distribution of temperature with elevation (Fig. 3), the positive temperature sum, $T_{\text {pos }}(z)$, can now be calculated using Equation (7) at any elevation on the glacier, using the daily minimum and maximum temperatures at Franz Josef village.

\subsection{Degree-day factors}

In the degree-day model, ablation is calculated using degree-day factors, which are determined empirically for this study on the basis of Equation (3), with different factors determined for snow and ice surfaces. To calculate degreeday factors using Equation (3), ablation and $T_{\text {pos }}$ are required. Ablation, $a$, was measured at intervals ranging 


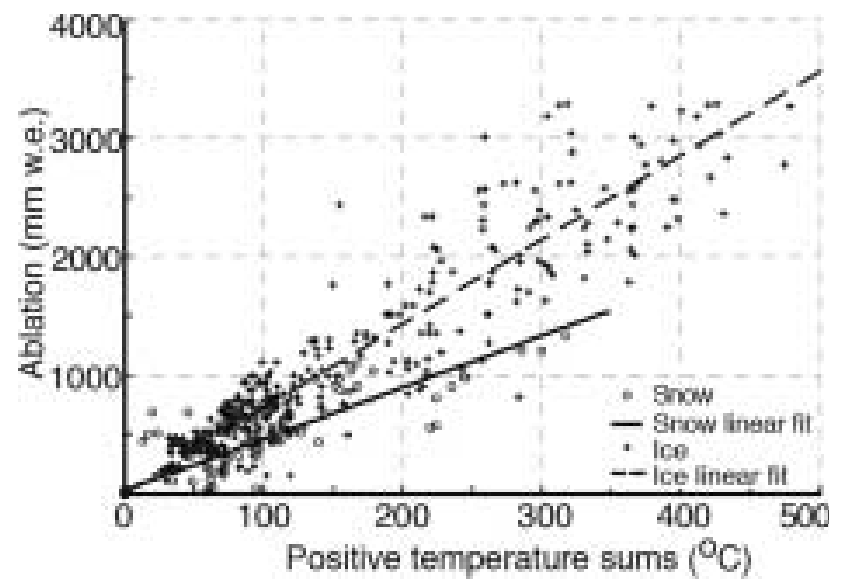

Fig. 4. Relationship between measured ablation and positive temperature sums, $T_{\text {pos, }}$ for snow and ice surfaces at Franz Josef Glacier. Ablation data are from mass-balance measurement sites over the period October 2000 to March 2003, with temperature lapsed to the measurement site from the nearest climate station (Fig. 1) using the lapse rate shown in Figure 3. The gradients of the linear regression shown for snow and ice define the degree-day factors, $k_{\mathrm{s}}$ and $k_{\mathrm{i}}$ respectively (see Equation (3)).

from 10 to 45 days at 34 stakes distributed across the glacier from 400 to 2500 ma.s.l. for the period October 2000 to March 2003. The positive temperature sum, $T_{\text {pos, }}$ was determined for each ablation measurement period for each stake from the temperature recorded at the nearest glacier climate station lapsed to the elevation of the stake using the empirically determined lapse rate (Fig. 3). The dataset is split into two subsets depending on whether the ablation measurement was made on an ice or snow surface. The gradients of the regression lines through the bivariate plots of $a-T_{\text {pos }}$ (Fig. 4) are the degree-day factors $k_{\mathrm{i}}$ and $k_{\mathrm{s}}$. The resulting degree-day factor for ice, $k_{\mathrm{i}}$, with its $95 \%$ confidence limits, is $7.17 \pm 0.20 \mathrm{~mm}$ w.e. $\mathrm{d}^{-1}{ }^{\circ} \mathrm{C}^{-1}$, and for snow, $k_{s}$ is $4.55 \pm 0.50 \mathrm{~mm}$ w.e. $\mathrm{d}^{-1}{ }^{\circ} \mathrm{C}^{-1}$. These values agree well with values in the literature, summarized by Braithwaite and others (2002) and Hock (2003).

For the purposes of modelling, and in order to apply the snow and ice degree-day factors correctly, a realistic snowdepth distribution is assumed, based on annual equilibriumline altitude (ELA) measurements at the start of modelling, and snow depth tracked in the model. Where the snow thickness is less than a critical value, in this case $0.1 \mathrm{~m}$ w.e. (cf. Jóhannesson, 1997), the degree-day factor is varied proportionally with the snow depth between the snow and the ice degree-day factor. The model is run for 10 years prior to the calibration and evaluation periods $2000-05$, to ensure any start-up effects resulting from the initial snow-thickness specification do not impact on model output.

\section{MASS-BALANCE MODEL EVALUATION}

In this section, before proceeding to reconstruct past mass balance and predict future mass balance, we evaluate the model by comparing its output with independent field measurements over the remaining 2 years of the measurement programme. In particular, we compare model predictions of the elevation distribution of annual net mass balance with various measurements of net annual mass balance, including the annual ELA, and examine the sensitivity of the

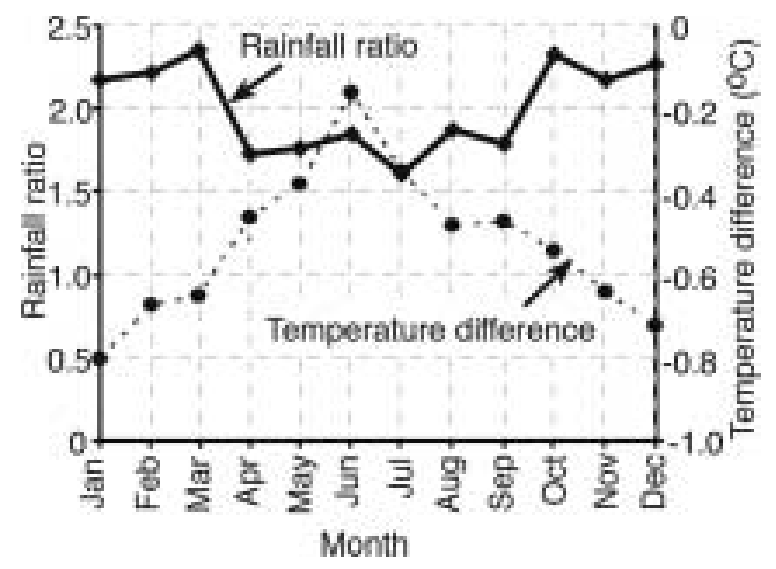

Fig. 5. Comparison of mean monthly temperature and monthly precipitation for climate stations at Franz Josef village and Hokitika for the period 1982-2003. The rainfall ratios are $>1$, indicating that rainfall is higher at Franz Josef village. The temperature differences are negative, indicating that Franz Josef village is cooler.

model to its input parameters. We also explore how consistent model output is, using the Hokitika and Franz Josef village stations as input, with the aim of using the more distant but longer-term Hokitika station for long-term massbalance reconstruction.

A comparison between the two climate datasets for 1982-2003 (the period of recording at the most recent Franz Josef village site) indicates some systematic seasonal differences between mean monthly rainfall rates and temperature at the two sites (Fig. 5). Franz Josef village has a winter minimum in rainfall, and a smaller seasonal temperature variation than Hokitika. The temperature and precipitation relationships in Figure 5 are used to transform Hokitika data to the Franz Josef village site to take into account these seasonal differences.

\subsection{Model sensitivity}

Sensitivity tests have been carried out to test the robustness of the model, with respect to the following input data and parameterizations within the model:

Franz Josef village input data

Precipitation distribution

Temperature distribution

Degree-day factors

Accumulation function

Ablation function.

The 'standard' run uses Hokitika climate data as input and all parameters as discussed in section 2. The Franz Josef village input data are used to test whether there is a difference between calculating mass balance using these data and the Hokitika data. The uncertainties in the temperature and precipitation distributions and the degree-day factors have been discussed earlier and these values are used for the sensitivity analysis. The sensitivity of the model to the accumulation and ablation functions is tested by removing them, and replacing the accumulation function with a simple temperature threshold based on the daily temperature, and replacing the ablation function with the daily temperature unless it is less than zero, in which case it is set to zero. 
Table 2. Modelled relative mass balance for 2000-05, and the results of the sensitivity analysis for this period. The standard values $\left(\mathrm{ma}^{-1}\right.$ w.e.) are calculated using climate data from Hokitika as input. Model sensitivity is shown as deviations from the standard values $\left(\mathrm{ma}^{-1}\right.$ w.e.) resulting from using climate data from Franz Josef village, and varying the model parameters within their uncertainty ranges

\begin{tabular}{lccccc} 
Run & \multicolumn{6}{c}{} \\
Standard & $2000 / 01$ & $2001 / 02$ & $2002 / 03$ & $2003 / 04$ & $2004 / 05$ \\
& 0.77 & -0.75 & 1.19 & 1.42 & 1.50 \\
\hline Franz Josef village & -0.26 & -0.56 & -0.02 & +0.04 & -0.94 \\
Min. degree-day factor & +0.28 & +0.39 & +0.28 & +0.25 & +0.27 \\
Max. degree-day factor & -0.28 & -0.39 & -0.27 & -0.25 & -0.26 \\
No ablation function & -0.46 & -0.52 & -0.42 & -0.41 & -0.37 \\
No accumulation function & -0.39 & -0.61 & -0.26 & -0.38 & -0.31 \\
Min. temperature & +0.36 & +0.43 & +0.32 & +0.33 & +0.31 \\
Max. temperature & -0.51 & -0.61 & -0.46 & -0.48 & -0.43 \\
Min. precipitation & -0.38 & -0.36 & -0.39 & -0.39 & -0.39 \\
Max. precipitation & +1.27 & +1.20 & +1.30 & +1.29 & +1.33
\end{tabular}

Using Franz Josef village input data yields a mass balance that is within the variation due to uncertainties in model parameters (Table 2), except in 2004/05, where the calculated mass balance is $0.94 \mathrm{ma}^{-1}$ w.e. less than the standard run. In 2004/05, there was a large precipitation event in June that was present in the Hokitika record but not the Franz Josef village record, which resulted in a significant difference in mass balance that persisted to the end of the balance year. In general, the net annual mass-balance calculations using the two datasets show a similar temporal pattern and there is not a systematic difference in the mass balance calculated (Table 2).

The model is not notably sensitive to the other parameters, with the variation in mass-balance calculation being relatively small (Table 2; Fig. 6). The range of calculated mass balance is dominated at higher elevations by the uncertainty in precipitation above $1700 \mathrm{~m}$ a.s.l. If the uncertainty in precipitation is neglected, the range in calculated mass balance is within $\pm 0.6 \mathrm{~m} \mathrm{a}^{-1}$ w.e.

\subsection{Annual mass-balance measurements}

Net annual mass-balance measurements were obtained in two ways. In the accumulation area, crevasse stratigraphy was used to obtain measurement of net accumulation at 10-15 sites at the end of each summer (March 2001 to March 2005; Fig. 1). This method is appropriate for measurement of accumulation in high-snowfall areas (Pelto,

1996, 1997), despite its limitations (Meier and others, 1997). Water equivalent was calculated from snow thickness measurements using a relationship between elevation and snow density developed on the adjacent Tasman Glacier (Ruddell, 1995) as follows:

$$
\rho=44.75 z^{-0.557}
$$

where $\rho$ is mean density for the annual snow layer, and $z$ is surface elevation. Densities varied between 590 and $650 \mathrm{~kg} \mathrm{~m}^{-3}$. The elevation of zero annual mass balance, equal to the ELA, has also been measured. In the ablation area, net annual mass balance was obtained by summation of short-term stake measurements of mass balance.

Annual accumulation measurements derived from these data (Fig. 6) show wide variability across a narrow elevation range, and in some years little relationship with elevation: for example, in the 2002/03 balance year, net annual accumulation values ranging from 2.8 to $8.2 \mathrm{mw}$.e. were obtained within a $60 \mathrm{~m}$ elevation range (Fig. 6c). Annual ablation data (Fig. 6) also indicate that net annual ablation is affected by variables other than elevation, but there is a clearer association with elevation than for accumulation.

The mass-balance data collected during the years ending March 2000 to March 2003 were used for model calibration, while data collected during the years ending March 2004 and March 2005 were reserved for model evaluation. Modelled results for all five years allow the calculation of net total mass balance for the glacier, indicating that the glacier experienced positive total annual mass balance relative to the 1986 geometry in all years except for 2001/02 (Table 2).

The measured mass-balance values also allow us to assess the model performance of previous modelling attempts (Woo and Fitzharris, 1992; Ruddell, 1995; Oerlemans, 1997), although as we must compare mean annual values from these models with measurements from this study over a few years, caution in interpretation is required. The net ablation measured near the terminus, of approximately $20 \mathrm{~m} \mathrm{a}^{-1}$ w.e., is similar to the model results of Woo and Fitzharris (1992) and Oerlemans (1997), but Ruddell (1995) overestimates ablation by a factor of two. The net accumulation measurements have a wide range as indicated above, but the results of Ruddell (1995) and Oerlemans (1997) are both within that range, while the $10 \mathrm{ma}^{-1}$ w.e. maximum estimated by Woo and Fitzharris (1992) is not approached.

\subsection{Measured and modelled mass balance}

The mass-balance measurements do not lie wholly within the range of variation prescribed by the uncertainty in the model parameters. There are clearly sources of massbalance variation which are not incorporated into the model and which we discuss later. The match is better for the last two evaluation years than the first three calibration years (Fig. 6). The model is not 'tuned' as such during the calibration years, but the ablation measurements are not independent of the model because the degree-day factors are calculated from measurements of temperature and ablation. Measured mass balance on the lower part of the glacier is generally less negative than modelled, consistent with the reduction in ablation from shading by the steep valley walls. The mismatch between modelled and measured mass balance is most obvious in the years 2000/01 and 2002/03 in the net accumulation measurements, where the modelled values are generally less positive than the measured values (Fig. 6).

There are a number of possible reasons for this discrepancy:

1. The net accumulation measurements are not accurate, perhaps due to incorrect density calculation or misidentification of annual layers.

2. The net accumulation measurements are accurate, but are not representative of the accumulation area as a whole, due to the high spatial variability observed.

3. The model does not take into account all causes of massbalance variation.

Each of these is possible, although we consider 2 and 3 the most likely. If the net accumulation measurements are 

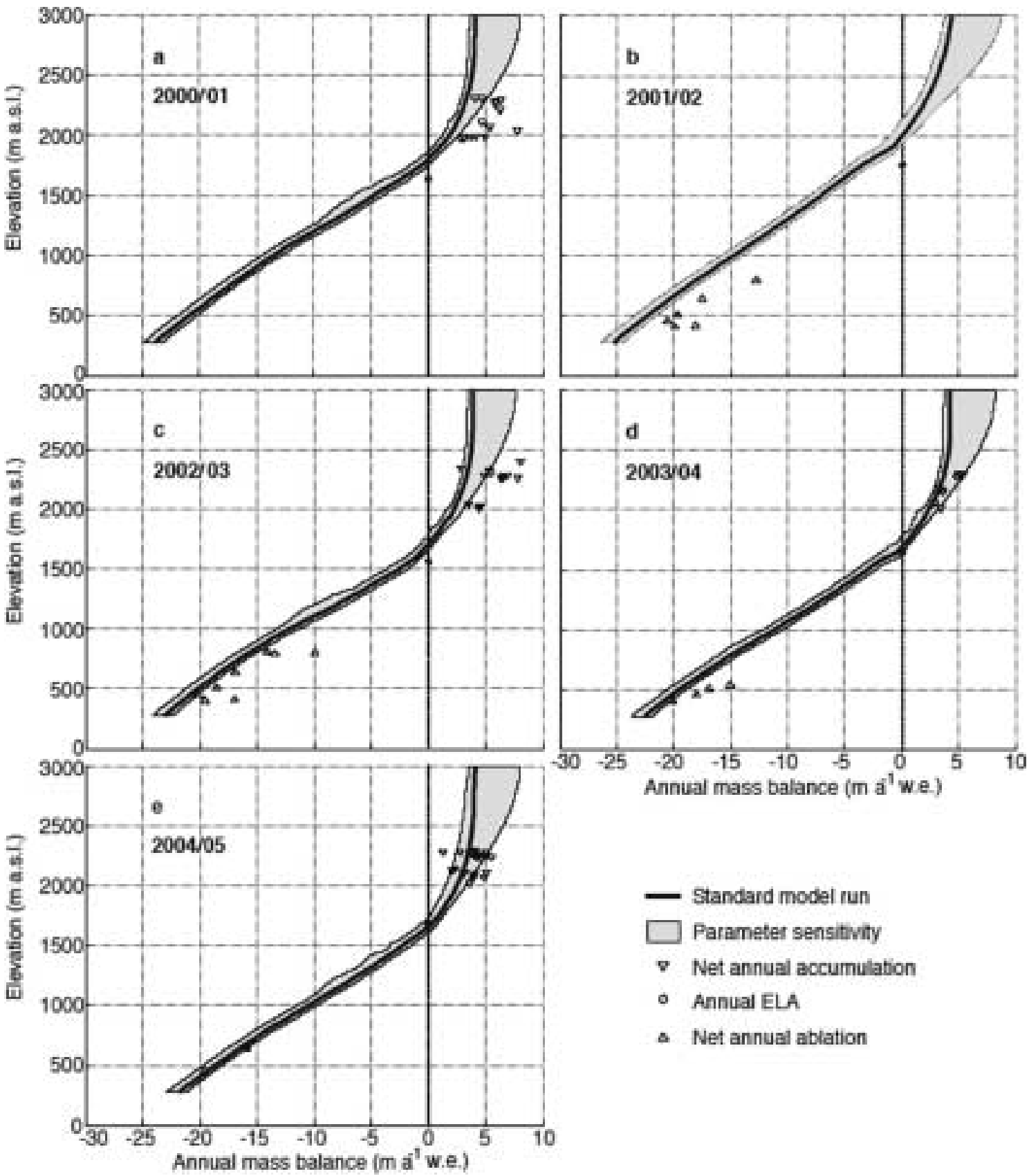

Annual mass balance ( $m a^{-1}$ we)

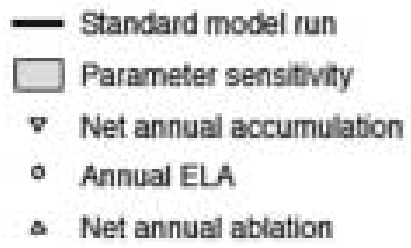

Fig. 6. Net annual balance modelled over the elevation range of the glacier. Data in $(\mathrm{a}-\mathrm{c})$ have been used for model calibration, while (d) and (e) are used for model evaluation. Mass-balance measurements are of three types: net accumulation from crevasse stratigraphy in the accumulation area; a measurement of the elevation of the annual ELA; and net ablation from stake measurements in the ablation area. Data are not available from all parts of the glacier in all years.

accurate and representative, then the precipitation must be twice as high in the elevation range $2000-2400$ ma.s.l. as assumed by the model in 2000/01 and 2002/03. This is unlikely given the precipitation measurement at Almer Hut, which constrains the precipitation at $1700 \mathrm{~m}$ a.s.l. (Fig. 2). However, it is also apparent that the model cannot simulate the observed high spatial variability because it occurs in a small elevation range, and the same set of parameters results in a better match in 2003/04 and 2004/05.

The degree-day model is constructed under the fundamental assumption that elevation, through its influence on temperature and precipitation, is the only spatial variable that affects mass balance. However, it is apparent that mass balance is affected by other spatial variables. Shading, aspect, slope and the presence of surface debris all affect ablation (Arnold and others, 1996), and redistribution of snow by wind affects accumulation (Purves and others, 1999). These processes are clearly significant on this glacier, and there is more variability in the relationship between measured mass balance and elevation at Franz Josef Glacier (Fig. 6) than for many other glaciers (e.g. Jóhannesson and others, 1995; Fountain and Vecchia, 1999; Braithwaite and Zhang, 2000).

In summary, the model simulates temporal patterns of mass-balance change and mass-balance variation with elevation well, with the exception of net accumulation in some years (Fig. 6). The Franz Josef village and Hokitika climate-data inputs result in similar patterns, with variations 


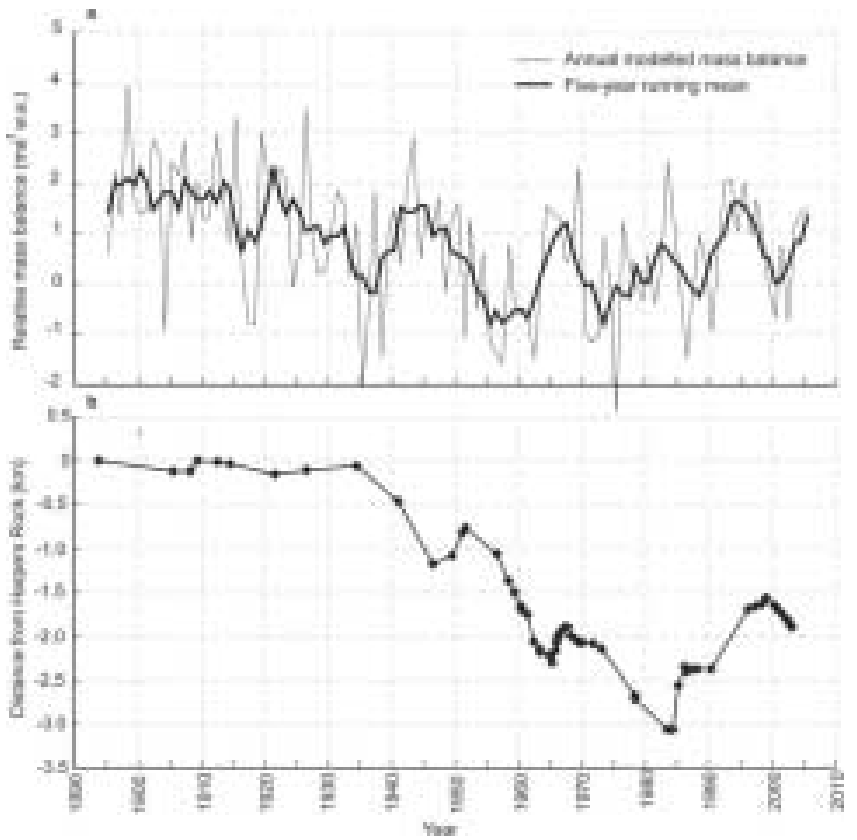

Fig. 7. (a) Relative mass-balance time series for the period 18942005 for Franz Josef Glacier modelled using the degree-day model in this study. Note that the mass balance is calculated relative to the 1986 glacier geometry. (b) Terminus position for Franz Josef Glacier, represented as distance from Harpers Rock. Terminus position is summarized by Ruddell (1995) up to 1991 and collected with global positioning system (GPS) since 1996 by the authors.

between the two ascribed to the simple method of extrapolation of temperature and precipitation between the stations. The model performs well outside the calibration period, indicating that using the Hokitika climate record to calculate Franz Josef Glacier mass balance is a valid approach to reconstructing past mass balance.

\section{PAST MASS BALANCE}

The mass-balance model is applied using the Hokitika climate data as input for the period 1894-2005. The resulting mass-balance time series indicates that there has been a systematic decrease in annual relative net mass balance at Franz Josef Glacier during the last century, at an average annual rate of $0.02 \mathrm{~m} \mathrm{a}^{-1}$ w.e. (Fig. 7). The change is not temporally uniform, with most of the reduction in mass balance occurring between the 1920s and the 1960s. The trend is small compared to the large interannual variability, which is typical of a maritime glacier at mid-latitudes (Oerlemans, 2000).

This systematic decrease in mass balance is reflected in a $3 \mathrm{~km}$ retreat of the glacier terminus between 1894 and 1984 . Because the mass balance is calculated on the 1986 geometry when the glacier was close to its 20th-century minimum extent, the mass balance is positive for $77 \%$ of the years, and the glacier retreats follow periods where the mass balance was less positive, rather than negative. The pattern of retreat can be correlated to the mass-balance reconstruction, with the trend of the 5 year running mean of modelled mass balance being reflected in the pattern of terminus advance and retreat (Fig. 7b). For example, the period of rapid terminus retreat between 1935 and the mid-1940s followed a period of consistently decreasing 5 year running mean of mass balance between 1920 and the late 1930s.
Table 3. The nature of the relationship between mass balance and climate parameters at Franz Josef Glacier, as indicated by the correlation between modelled mass balance and temperature and precipitation on an annual and seasonal timescale. The correlation coefficient $r$ is calculated using 111 years of data

\begin{tabular}{lcc}
\hline Season & Temperature & Rainfall \\
& $r$ & $r$ \\
\hline Annual & 0.86 & 0.41 \\
Winter & 0.56 & 0.17 \\
Summer & 0.88 & 0.39 \\
\hline
\end{tabular}

The short-term readvances in the late 1940s and 1960s are preceded by periods of increasing mass balance. The dramatic and long-lived advances of the 1980s and 1990s are also preceded by periods of increasing mass balance, but the mass-balance change was no bigger than the perturbations that caused the smaller advances of the 1940s and 1960s. While there are clearly strong links between the modelled mass balance and terminus position, the relationship between mass balance and terminus position cannot be rigorously assessed without an ice flow model. This will be considered in a companion paper.

There has been debate in the literature over whether temperature or precipitation is the dominant driver of the 20th-century behaviour of Franz Josef Glacier (Suggate, 1950; Hessell, 1983; Hooker and Fitzharris, 1999). All of the studies that have tried to answer this question empirically have attempted to correlate temperature and precipitation with glacier advance and retreat. The non-linear response of the glacier to mass-balance perturbations, shown by our results, makes this approach problematic. An alternative approach is to correlate temperature and precipitation with the mass-balance reconstruction directly, hence removing glacier response from the equation. The results (Table 3) indicate that modelled mass balance at Franz Josef Glacier is only weakly correlated with precipitation, even when precipitation is split into seasonal components. In contrast, there is a strong relationship between temperature and mass balance, particularly when only summer temperature is included. This result corroborates other modelling studies (Ruddell, 1995; Oerlemans, 1997) which concluded that Franz Josef Glacier is not notably sensitive to changes in precipitation, and supports the inference that the temperature sensitivity of glaciers increases in high-precipitation environments (Oerlemans, 2001).

\section{FUTURE MASS BALANCE}

The IPCC predicts global mean annual temperature increases of $2-4.5^{\circ} \mathrm{C}$ over the next century (Houghton and others, 2001). These predictions for global climate have been spatially downscaled using statistical methods which describe how New Zealand's regional climate deviates from the large-scale background climate, primarily because of orographic effects (Mullan and others, 2001). The result is an estimate of the likely effects of the range of IPCC global climate-change scenarios on monthly changes in precipitation and temperature at Hokitika over the next 100 years. These estimates are used for the purpose of modelling future mass balance at Franz Josef Glacier. 


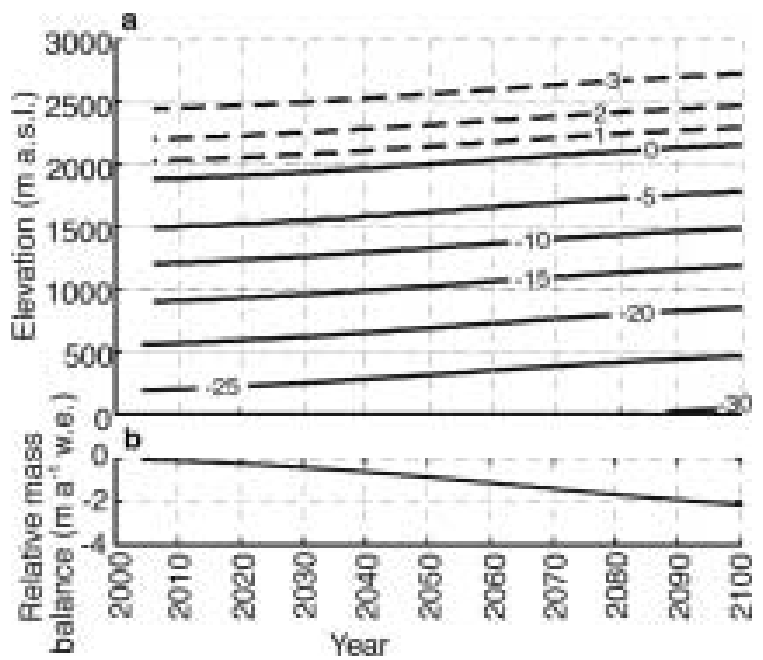

Fig. 8. (a) The modelled change in mass balance (in $\mathrm{m} \mathrm{a}^{-1}$ w.e.) for the 'mean warming' future climate scenario from 2005 to 2100. (b) The relative mass-balance change over this time.

In order to investigate the range of possible mass-balance outcomes for the next century, we explore the mass-balance implications of four regionally downscaled future climate scenarios, based on the uncertainty in global warming scenarios, as follows:

1. A minimum warming scenario;

2. A mean warming scenario;

3. A maximum warming scenario;

4. A 'no warming' scenario, in which temperature and rainfall are both held at their 1970-99 means for Hokitika through to 2100.

In each of the scenarios 1-3 the mean regional downscaling sensitivities of temperature and precipitation at Hokitika are used at monthly resolution, taking into account the predicted seasonal changes (personal communication from B.Mullan, 2003). In order to calculate mass-balance sensitivity changes to temperature increase alone, a further scenario with a temperature increase of $2^{\circ} \mathrm{C}$ over the next century and no change in precipitation is examined (Oerlemans and others, 1998). The temperature and precipitation changes associated with each of these scenarios are indicated in Table 4.

The 'no warming' scenario results in a mass balance of $0.1 \mathrm{ma}^{-1}$ w.e., indicating that the present-day (1970-99) climate results in a mass balance that is slightly positive on the 1986 geometry. In this case, the ELA is at $1860 \mathrm{~m}$, and the accumulation area is $28 \mathrm{~km}^{2}$.

Under the mean warming scenario, in which a $1.4^{\circ} \mathrm{C}$ temperature increase occurs with a $15 \%$ increase in precipitation, the mass-balance distribution changes markedly (Fig. 8). The change is most pronounced at lower elevations, where the ablation increases by almost $5 \mathrm{~m} \mathrm{a}^{-1}$ w.e. during the period. At high elevations the change is less pronounced, as the mean annual temperature at $3000 \mathrm{~m}$ a.s.I. is still $-2.6^{\circ} \mathrm{C}$, ensuring that there is little melt and almost all precipitation still falls as snow. The annual mass balance in 2100 is $2.4 \mathrm{~m} \mathrm{a}^{-1}$ w.e. less than the present day (Table 4). The ELA rises to 2160 m a.s.I., which reduces the accumulation area by $34 \%$ compared to the present day.

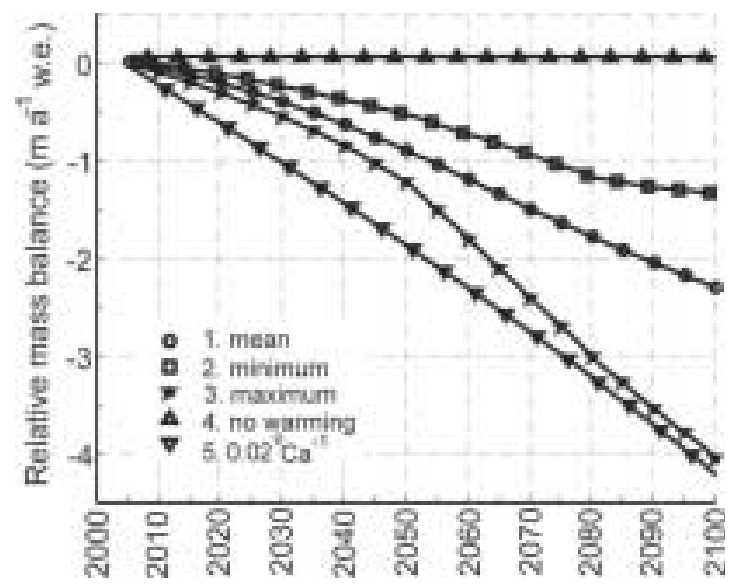

Fig. 9. The range of relative mass-balance variations for the period 2005-2100 calculated using each of the four climate-change scenarios. The $0.02{ }^{\circ} \mathrm{Ca}^{-1}$ warming is included to assess the sensitivity of the glacier to a linear warming.

The maximum warming scenario, which combines a $2.2^{\circ} \mathrm{C}$ increase in temperature with a $+23 \%$ change in precipitation, results in a decrease in mass balance of $4.2 \mathrm{~m} \mathrm{a}^{-1}$ by 2100 (Fig. 9). Under this scenario the ELA rises to $2320 \mathrm{~m}$ a.s.l., reducing the accumulation area by $66 \%$ compared to the present day. This outcome occurs in response to local warming that is less than the mean annual global temperature change predicted for the period. If sustained, the warming would have serious consequences for the sustainability of the glacier, leaving only a series of small cirque glaciers.

The minimum warming scenario, in its combination of a moderate warming $\left(0.9^{\circ} \mathrm{C}\right)$ with a moderate increase in precipitation of $+10 \%$ (Table 4 ), reduces the mass balance by $1.4 \mathrm{~m} \mathrm{a}^{-1}$ from the present day to 2100 . The ELA rises to 2060 ma.s.l., reducing the accumulation area by $18 \%$ compared to the present day.

The mean warming scenario represents a sensitivity to climate warming of $-1.6 \mathrm{~m} \mathrm{a}^{-1}$ w.e. ${ }^{\circ} \mathrm{C}^{-1}$, which is a greater temperature sensitivity than previously reported in the literature (Braithwaite and others, 2002). With no precipitation increase (using the $0.02^{\circ} \mathrm{Ca}^{-1}$ scenario), the sensitivity is even greater, at $-1.9 \mathrm{~m} \mathrm{a}^{-1}$ w.e. ${ }^{\circ} \mathrm{C}^{-1}$. Braithwaite and

Table 4. Mean annual changes in Hokitika precipitation and temperature from present-day values for each of the future climate scenarios. The resulting change in annual ELA and mass balance between the present day and 2100 is shown

\begin{tabular}{|c|c|c|c|c|c|}
\hline \multirow{3}{*}{ Scenario } & \multicolumn{3}{|c|}{ Model input } & \multicolumn{2}{|c|}{ Model output 2100} \\
\hline & $\begin{array}{l}\text { Global } \\
\text { temp. }\end{array}$ & $\begin{array}{c}\text { Hokitika } \\
\text { temp. }\end{array}$ & $\begin{array}{l}\text { Hokitika } \\
\text { precip. }\end{array}$ & ELA & $\begin{array}{c}\text { Mass } \\
\text { balance }\end{array}$ \\
\hline & ${ }^{\circ} \mathrm{C}$ & ${ }^{\circ} \mathrm{C}$ & $\%$ & ma.s.I. & $\mathrm{m} \mathrm{a}^{-1}$ w.e. \\
\hline Min. warming & +1.8 & +0.9 & +10 & 2060 & -1.3 \\
\hline Mean warming & +2.8 & +1.4 & +15 & 2160 & -2.3 \\
\hline Max. warming & +4.3 & +2.2 & +23 & 2320 & -4.1 \\
\hline $0.02^{\circ} \mathrm{Ca}^{-1}$ & +2.0 & +2.0 & 0 & 2420 & -4.2 \\
\hline No warming & 0 & 0 & 0 & 1860 & 0.1 \\
\hline
\end{tabular}


others (2002) reported a variation of sensitivity from -0.1 to $-1.2 \mathrm{~m} \mathrm{a}^{-1}$ w.e. ${ }^{\circ} \mathrm{C}^{-1}$ for 61 glaciers and ice caps and noted that higher sensitivity was associated with warm wet maritime environments. Oerlemans and others (1998) calculated a sensitivity of $-1.3 \mathrm{~m} \mathrm{a}^{-1}$ w.e. ${ }^{\circ} \mathrm{C}^{-1}$ for Franz Josef Glacier. The high sensitivity found here reflects the maritime environment but may also result from the fact that the comparison period of 1970-99 was characterized by a high incidence of El Ninõ events, leading to cool temperatures, high precipitation and glacier advance in New Zealand (Chinn and others, 2005).

\section{CONCLUSION}

We have developed a robust degree-day model that is constrained by field measurement, and which is able to simulate measured variation of mass balance with elevation at Franz Josef Glacier. A sensitivity analysis of the model shows that the major uncertainty is in the values of precipitation and accumulation at high elevations.

The model indicates that the relative mass balance of Franz Josef Glacier has been decreasing at an average annual rate of $0.02 \mathrm{~m} \mathrm{a}^{-1}$ w.e. for the last 111 years, with the main reduction in mass balance between the 1920s and 1960s. Analysis of the relationship between annual mass balance and key climate parameters indicates that this reduction in mass balance is strongly correlated to changes in temperature $(r=0.86)$, and only weakly correlated to changes in precipitation $(r=0.41)$. The decadal pattern of variation of mass balance over the period 1894-2005 is broadly reflected in the observed variation in terminus position, and in particular in the retreat of up to $3 \mathrm{~km}$ during that time.

In a mean regional warming scenario, the mass balance of Franz Josef Glacier will continue to reduce at the same average annual rate, $0.02 \mathrm{ma}^{-1}$ w.e., with the net mass balance reducing by a total of $2.4 \mathrm{~m} \mathrm{a}^{-1}$ w.e. by 2100 . Under a maximum warming scenario, the net mass balance in 2100 will reduce by $4.1 \mathrm{~m} \mathrm{a}^{-1}$ w.e. The sensitivity to climate warming is greater than previously reported for any glacier, at $-1.9 \mathrm{ma}^{-1}$ w.e. ${ }^{\circ} \mathrm{C}^{-1}$.

In obtaining empirical evidence to calibrate and evaluate the model, we have measured the largest rate of ablation ( $\sim 20 \mathrm{~m} \mathrm{a}^{-1}$ w.e.) reported in the literature (Haeberli and others, 2001), and high rates of accumulation of up to $8 \mathrm{~m} \mathrm{a}^{-1}$ w.e. in the elevation range $1800-2300 \mathrm{~m}$ a.s.l. These rates, with the topographic configuration and high velocity, account for the extreme sensitivity of Franz Josef Glacier to climate change. Our measurements also indicate the extent to which there is significant variation in mass balance that is not explained by elevation. This result reinforces the need for detailed field measurements to enable understanding of the degree of uncertainty attached to the results of massbalance models.

\section{ACKNOWLEDGEMENTS}

We acknowledge all those who have given time to help with the sometimes arduous task of maintaining stakes on lower Franz Josef Glacier, especially L. Kees, T. Kerr, P. Clendon, B. de Passille and other students at Canterbury University. B. Mullan of the National Institute of Water and Atmospheric Research (NIWA), New Zealand, kindly provided Hokitika climate-change scenarios, and R. Henderson, also of NIWA, provided helpful discussion about precipitation and data from Almer Hut. The manuscript was improved by helpful comments from $\mathrm{H}$. Rott, R. Braithwaite, M. Sharp and E.J. Klok. The work would not be possible without the glacier guides who maintain the tracks on the glacier, and provide information on glacier conditions. The New Zealand Department of Conservation gave permission for fieldwork. This work was supported by University of Canterbury grant UC6474.

\section{REFERENCES}

Anderson, B. 2004. The response of Ka Roimata o Hine Hukatere Franz Josef Glacier to climate change. (PhD thesis, University of Canterbury.)

Arnold, N.S., I.C. Willis, M.J. Sharp, K.S. Richards and W.J. Lawson. 1996. A distributed surface energy-balance model for a small valley glacier. I. Development and testing for Haut Glacier d'Arolla, Valais, Switzerland. J. Glaciol., 42(140), 77-89.

Barringer, J.R.F. 1989. A variable lapse rate snowline model for the Remarkables, Central Otago, New Zealand. J. Hydrol. (NZ), 28(1), 32-46.

Braithwaite, R.J. and Y. Zhang. 2000. Sensitivity of mass balance of five Swiss glaciers to temperature changes assessed by tuning a degree-day model. J. Glaciol., 46(152), 7-14.

Braithwaite, R.J., Y. Zhang and S.C.B. Raper. 2002. Temperature sensitivity of the mass balance of mountain glaciers and ice caps as a climatological characteristic. Z. Gletscherkd. Glazialgeol., 38(1), 2001, 35-61.

Chinn, T., S. Winkler, M.J. Salinger and N. Haakensen. 2005. Recent glacier advances in Norway and New Zealand: a comparison of their glaciological and meteorological causes. Geogr. Ann., 87(1), 141-157.

Denton, G.H. and C.H. Hendy. 1994. Younger Dryas age advance of Franz Josef Glacier in the Southern Alps of New Zealand. Science, 264(5164), 1434-1437.

Fountain, A.G. and A. Vecchia. 1999. How many stakes are required to measure the mass balance of a glacier? Geogr. Ann., 81A(4), 563-573.

Gellatly, A.F. and D.A. Norton. 1984. Possible warming and glacier recession in the South Island, New Zealand. New Zeal. J. Bot., 27, 381-388.

Griffiths, G.A. and M.J. McSaveney. 1983. Distribution of mean annual precipitation across steep land regions of New Zealand. New Zeal. J. Science, 26(2), 197-209.

Grove, J.M. 1988. The Little Ice Age. London and New York, Methuen.

Haeberli, W., R. Frauenfelder and M. Hoelzle, eds. 2001. Glacier Mass Balance Bulletin No. 6 (1998-1999). Zürich, International Commission on Snow and Ice of the International Association of Hydrological Sciences; Nairobi, United Nations Environment Programme; Paris, UNESCO.

Harper, A.P. 1894. The Franz Josef Glacier. Appendix to the Journal of the House of Representatives of New Zealand. C-1, Appendix No. 6, 75-79.

Henderson, R.D. and S.M. Thompson. 1999. Extreme rainfalls in the Southern Alps of New Zealand. J. Hydrol. (NZ), 38(2), 309-330.

Hessell, J.W.D. 1983. Climatic effects on the recession of the Franz Josef Glacier. New Zeal. J. Sci., 26(3), 315-320.

Hock, R. 2003. Temperature index melt modelling in mountain areas. J. Hydrol., 282(1-4), 104-115.

Hooker, B.L. and B.B. Fitzharris. 1999. The correlation between climatic parameters and the retreat and advance of Franz Josef Glacier, New Zealand. Global Planet. Change, 22(1-4), 39-48.

Houghton, J.T. and 7 others. 2001. Climate change 2001: the scientific basis. Contribution of Working Group I to the Third Assessment Report of the Intergovernmental Panel on Climate Change. Cambridge, etc., Cambridge University Press. 
Jóhannesson, T. 1997. The response of two Icelandic glaciers to climatic warming computed with a degree-day glacier massbalance model coupled to a dynamic glacier model. J. Glaciol., 43(144), 321-327.

Jóhannesson, T., T. Laumann and M. Kennett. 1995. Degree-day glacier mass-balance modelling with applications to glaciers in Iceland, Norway and Greenland. J. Glaciol., 41(138), 345-358.

Lowell, T.V. and 8 others. 1995. Interhemispheric correlation of late Pleistocene glacial events. Science, 269(5230), 1541-1549.

Meier, M.F., R. Armstrong and M.B. Dyurgerov. 1997. Correspondence. Comments on "Annual net balance of North Cascade glaciers, 1984-94" by Mauri S. Pelto. J. Glaciol., 43(143), 192-193.

Moore, R.D. and I.F. Owens. 1984. Modelling alpine snow accumulation and ablation using daily climate observations. J. Hydrol. (NZ), 23(2), 73-83.

Mullan, A.B., D.S. Wratt and J.A. Renwick. 2001. Transient model scenarios of climate changes for New Zealand. Weather Climate, 21, 3-34.

Oerlemans, J. 1997. Climate sensitivity of Franz Josef Glacier, New Zealand, as revealed by numerical modeling. Arct. Alp. Res., 29(2), 233-239.
Oerlemans, J. 2000. Holocene glacier fluctuations: is the current rate of retreat exceptional? Ann. Glaciol., 31, 39-44.

Oerlemans, J. 2001. Glaciers and climate change. Lisse, etc., A.A. Balkema.

Oerlemans, J. and 10 others. 1998. Modelling the response of glaciers to climate warming. Climate Dyn., 14(4), 267-274.

Pelto, M.S. 1996. Annual net balance of North Cascade glaciers, 1984-94. J. Glaciol., 42(140), 3-9.

Pelto, M.S. 1997. Correspondence. Reply to comments of Meier and others on "Annual net balance of North Cascade glaciers, 1984-94" by Mauri S. Pelto. J. Glaciol., 43(143), 193-196.

Purves, R.S., W.A. Mackaness and D.E. Sugden. 1999. An approach to modelling the impact of snow drift on glaciation in the Cairngorm Mountains, Scotland. J. Quat. Sci., 14(4), 313-321.

Ruddell, A.R. 1995. Recent glacier and climate change in the New Zealand Alps. (PhD thesis, University of Melbourne.)

Salinger, M.J. 1981. New Zealand climate: the instrumental record. (PhD thesis, Victoria University, Wellington.)

Suggate, R.P. 1950. Franz Josef and other glaciers of the Southern Alps, New Zealand. J. Glaciol., 1(8), 422-429.

Woo, M. and B.B. Fitzharris. 1992. Reconstruction of mass-balance variations for Franz Josef Glacier, New Zealand. Arct. Alp. Res., 24, 281-290.

MS received 26 September 2005 and accepted in revised form 28 September 2006 